\title{
Usos productivos y apropiación de los recursos naturales en el espacio rural del municipio de Santa María de Jetibá (Es-Brasil)
}

\author{
Anderson Pereira Portuguez \\ Universidad Federal de Uberlândia, Brasil \\ Universidad Estatal de Ceará, Brasil \\ anderson@pontal.ufu.br
}

Recibido:30 de enero de 2012

Enviado a evaluar: 25 de abril de 2012

Aceptado: 9 de julio de 2012

\section{RESUMEN}

El objetivo de la presente investigación fue diagnosticar los usos productivos del espacio rural del municipio de Santa María de Jetibá, ubicado en el Estado de Espírito Santo (Brasil), así como los modos de apropiación de los recursos naturales por la población local. Para ello, se efectuó una revisión bibliográfica, análisis documental y trabajos de campo entre los años 2005 y 2010 en diversas haciendas para la realización de entrevistas y fotografías. Se concluyó que la productividad rural se asienta principalmente en la pequeña propiedad familiar y que las producciones cafetera, hortícola y de granja son las más importantes. Se constató que el modelo de apropiación de los recursos naturales ha generado la fragmentación forestal en escala local, lo que pone a una serie de especies tropicales en riesgo de extinción. Se observó, finalmente, que las comunidades rurales necesitan orientaciones técnicas para un mejor manejo de los recursos naturales que disponen.

Palabras clave: Espacio Rural, Producción, Recursos Naturales, Sustentabilidad, Brasil.

\section{Productive Uses and Ownership of Natural Resources in Rural Areas of the Municipality of Santa María de Jetibá (Es-Brazil)}

\begin{abstract}
The present investigationaimed todiagnose theproductive usesof rural landin the municipality of Santa Maria de Jeribá, located in the state of Espírito Santo (Brasil), well asthe modes of appropriationof natural resourcesby local population. To this end, wereperformeda literature review, documentary analysis and fieldworkbetween the yearsof 2005and 2010in severalfarms to realizeinterviewsand photos. Was concluded thatrural productivityis basedmainlyonsmall family properties and the coffee and horti-farmer productionsare the most important. Was foundthat the pattern ofownershipof natural resourceshas generatedtheforest fragmentationon a local scale, which putsanumber oftropical species indanger of extinction.There was, finally, that rural communitiesneedtechnical guidelinesfor better managementof natural resourcesthathave.
\end{abstract}

Key words: Rural Space, Production, Natural Resources, Sustainability, Brazil. 


\title{
Utilisations productives et appropriation des ressources naturelles dans l'espace rural de la municipalité de Santa María de Jetibá (Es-Brasil)
}

\begin{abstract}
RÉSUMÉ
La Présente recherche a eu l'objectif de diagnostiquer les utilisations productives de l'espace rurale de la ville de Santa Maria de Jeribá, localisé dans l’État du Espírito Santo (Brésil), ainsi que les modes d'appropriation des ressources naturelles par la population locale. Pour de telle façon, il s'être réalisé une révision bibliographique, l'analyse de document et travaux de champ entre les années de 2005 et 2010 dans plusieurs fermes pour la réalisation d'interviews et de photographies. On a conclu que la productivité rurale s'est basée principalement dans petite propriété familière et les productions de café, animale, végétale et des légumes sont les plus importantes. S'estconstaté que la norme d'appropriation des ressources naturelles a produit la fragmentation forestière dan séchelle locale, ce qui met une série d'espèces tropicales en danger d'extinction. Il a été observé, finalement, que les communautés rurales ont besoin d'orientations techniques pour un meilleur straitement des ressources naturelles qui disposent.
\end{abstract}

Mots-clés: Espace Rurale, Production, Ressources Naturelles, Développement Durable, Brésil.

\section{INTRODUCCIÓN}

Este trabajo relata una investigación académica realizada en el medio rural del municipio de Santa María de Jetibá, ubicado en el Estado brasileño de Espírito Santo, en el cual históricamente las formas de uso y ocupación del espacio provocaron profundas transformaciones en la dinámica ambiental, con graves consecuencias, tanto para la naturaleza en sí, como para la sociedad local.

El interés por este municipio fue despertado en 2004 cuando el autor participó de una de las acciones emprendidas por el Instituto de Investigación del Bosque Atlántico - IPEMA - para ejecutar las acciones del proyecto Viabilidad Poblacional del Muriqui, Brachyteles hypoxanthus (Primates, Atelidae), en fragmentos del Bosque Atlántico en el Estado de Espírito Santo - FASE II. De 2005 a 2010, inclusive después de la finalización de las actividades con el IPEMA, el autor se mantuvo interesado en investigar Santa María de Jetibá, en especial sus aspectos geográficos y turísticos.

Hasta mediados del siglo XIX, el área actualmente correspondiente al municipio de Santa María de Jetibá era prácticamente deshabitada, con registros de unas pocas tribus indígenas habitando los valles escarpados de la región serrana de Espírito Santo. Sin embargo, a partir de la incorporación de esta porción del Estado a la gran área cafetera de Brasil, los bosques tropicales fueron rápidamente devastados por el avance de las plantaciones destinadas, sobre todo, a la exportación.

Ya en la segunda mitad del siglo XX, después de la decadencia de la caficultura y la diversificación económica de Brasil, el municipio se integró al llamado cinturón verde, que corresponde al conjunto de espacios destinados a la producción hortícola, frutícola y de granja para el abastecimiento del mercado de la Región Metropolitana de Vitória (capital del Estado de Espírito Santo). Estas actividades coexisten en la actualidad, juntamente con la ganadería bovina y porcina. 
Figura 1. Ubicación del Municipio de Santa María de Jetibá (ES/Brasil).

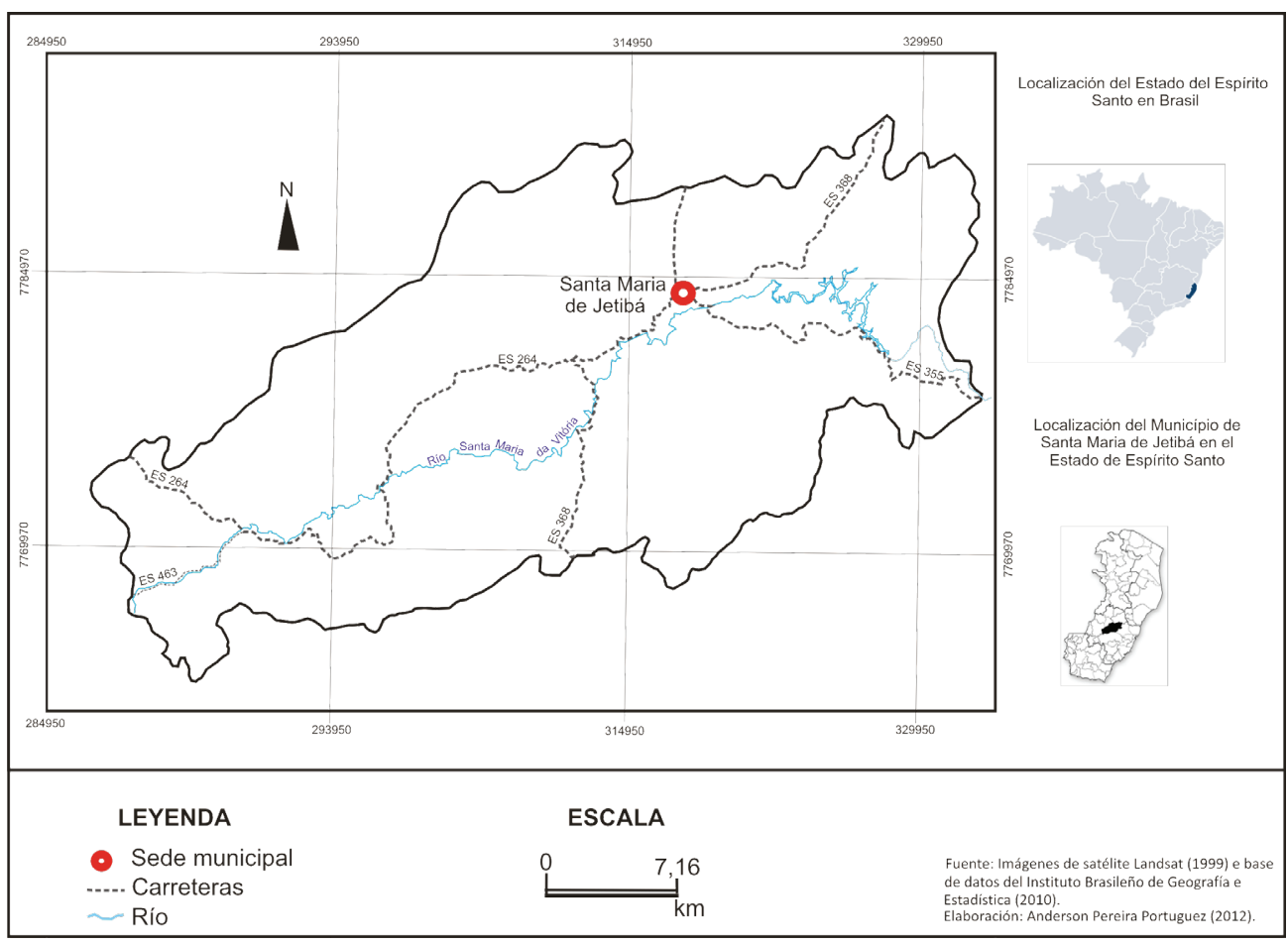

Fuente: Elaboración propia.

El análisis ahora presentado se basó en búsquedas bibliográficas, análisis documental y trabajos de campo. La revisión del material publicado fue realizada en el Archivo Público Estatal y en las bibliotecas de la Universidad Federal de Espírito Santo, biblioteca del IPEMA - Instituto de Investigación del Bosque Atlántico, Ayuntamiento Municipal de Santa María de Jetibá, entre otros lugares de investigación.

Para el levantamiento de datos primarios sobre la experiencia ambiental y las perspectivas de desarrollo sustentable en las comunidades rurales de Santa María de Jetibá, se realizaron diversos viajes al municipio, durante los cuales se definieron tres trayectos de cobertura de su medio rural, siempre partiendo del Distrito Sede.

En la sede del municipio, se recolectó una serie de datos referentes a su proceso histórico, buscando entender en que contexto se dio la inmigración europea hacia esa región de Espírito Santo. Estos datos permitieron comprender determinados comportamientos culturales que pueden ser de gran utilidad para planificaciones futuras. Se cree que intervenir en una colectividad a favor de la protección de sus recursos naturales y a favor de un modelo más apropiado de ordenamiento territorial en escala local, presupone acciones compatibles con su historia, su cultura y su identidad.

En relación a la investigación cuali-cuantitativa realizada en el medio rural, se entrevistaron a 17 propietarios (muestra aleatoria) de un total de 56 informantes poten- 
ciales, lo que corresponde al 30,35\% del universo. De este modo, la muestra superó la recolección mínima del 10\% del total de posibles testimonios, de acuerdo a las recomendaciones dadas por Piana et al. (2009), para estudios de esta naturaleza. La tabla 1, a continuación, presenta las comunidades rurales seleccionadas para la investigación y el número de propiedades identificadas en cada una de ellas.

Tabla 1. Número de Propiedades por comunidad rural investigada.

\begin{tabular}{l|c|c|c}
\hline \multicolumn{1}{c|}{$\begin{array}{c}\text { Comunidad } \\
\text { Rural }\end{array}$} & $\begin{array}{c}\text { Número de propietarios } \\
\text { visitados }\end{array}$ & $\begin{array}{c}\text { Número de } \\
\text { entrevistas realizadas }\end{array}$ & $\%$ \\
\hline $\begin{array}{l}\text { São Sebastião de } \\
\text { Belém }\end{array}$ & 11 & 4 & 36,36 \\
\hline $\begin{array}{l}\text { Rio das Pedras y } \\
\text { Córrego do Ouro }\end{array}$ & 23 & 8 & 34,7 \\
\hline $\begin{array}{l}\text { Barra del río } \\
\text { Possmoser }\end{array}$ & 9 & 3 & 33,33 \\
\hline $\begin{array}{l}\text { Santa María y Rio } \\
\text { Possmoser }\end{array}$ & 13 & 02 & 15,38 \\
\hline Total & $\mathbf{5 6}$ & $\mathbf{1 7}$ & $\mathbf{3 0 , 3 5}$ \\
\hline
\end{tabular}

Fuente: Elaboración propia.

Las entrevistas siguieron una guía semi-abierta que permitía a los respondientes adornarlas con comentarios para enriquecer la recogida de informaciones. Los testimonios fueron grabados por equipos electrónicos, almacenados en medio digital, transcriptos e interpretados siguiendo los preceptos metodológicos propuestos por Silva (2009).

Por tratarse de una comunidad atípica, en la cual muchos de los integrantes se comunican en la lengua ancestral conocida como pomerano ${ }^{1}$, fueron necesarios algunos procedimientos para conocer la dinámica cultural local (aun de forma superficial). La opción por el diálogo individual registrado se debió, inclusive, a ese hecho, pues en algunos casos los propietarios sentían dificultades en comprender al entrevistador, requiriendo la participación de una traductora.

Finalmente, hay que aclarar que algunos de los datos ahora presentados derivan de la observación directa con registro fotográfico, siguiendo los preceptos metodológicos recomendados por Justiniano (2009). Este recurso metodológico ha sido utilizado para la generación de datos en localidades poco representadas en la literatura.

${ }^{1}$ Según Medeiros (1997), la lengua nativa de los pomeranos era llamada Pomedod. Sin embargo, estudios realizados por Rölke (1996) apuntan a una variación de la lengua Wende, que sufrió contribuciones de otros dialectos en ocasión del asentamiento germánico en la región de origen de los inmigrantes. 


\section{UBICACIÓN Y CARACTERIZACIÓN DEL ÁREA ESTUDIADA}

Santa María de Jetibá se ubica en la región serrana central del Estado de Espírito Santo, cerca de $80 \mathrm{~km}$ de Vitória, la capital estatal. De acuerdo a los datos del censo IBGE - Instituto Brasileño de Geografía y Estadística, el municipio posee un área de $735,555 \mathrm{~km}^{2}$ y una población absoluta de 34.176 habitantes, en donde 11.797 viven en el área urbana y 22.379 habitan en el medio rural (IBGE, 2010)². Su ocupación es reciente, desde la segunda mitad del siglo XIX.

La porción serrana central de Espírito Santo, al igual que la mayor parte del territorio de este Estado, está formada por terrenos antiguos, pertenecientes al reborde atlántico del escudo brasileño, con predominio de formaciones geológicas que se remontan al período pre-cambriano (Moraes, 2004). A estas formaciones corresponden el 70 al $75 \%$ del territorio y se presentan como secuencias basculares de sierras escarpadas.

De acuerdo con la $\mathrm{PMSMJ}^{3}$ (2001), Santa María de Jetibá se halla situada en la zona central de esa formación, en los terrenos ubicados al sur del río Doce, donde las altitudes son de moderadas a bajas, con picos de entre alrededor de $350 \mathrm{~m}$ en la región de Suiça, a 1.462m en el Distrito de São João de Garrafão, donde se destaca uno de los marcos del paisaje municipal: el pico del Garrafão con 710m (fig. 2).

Figura 2. Piedra del Garrafão.

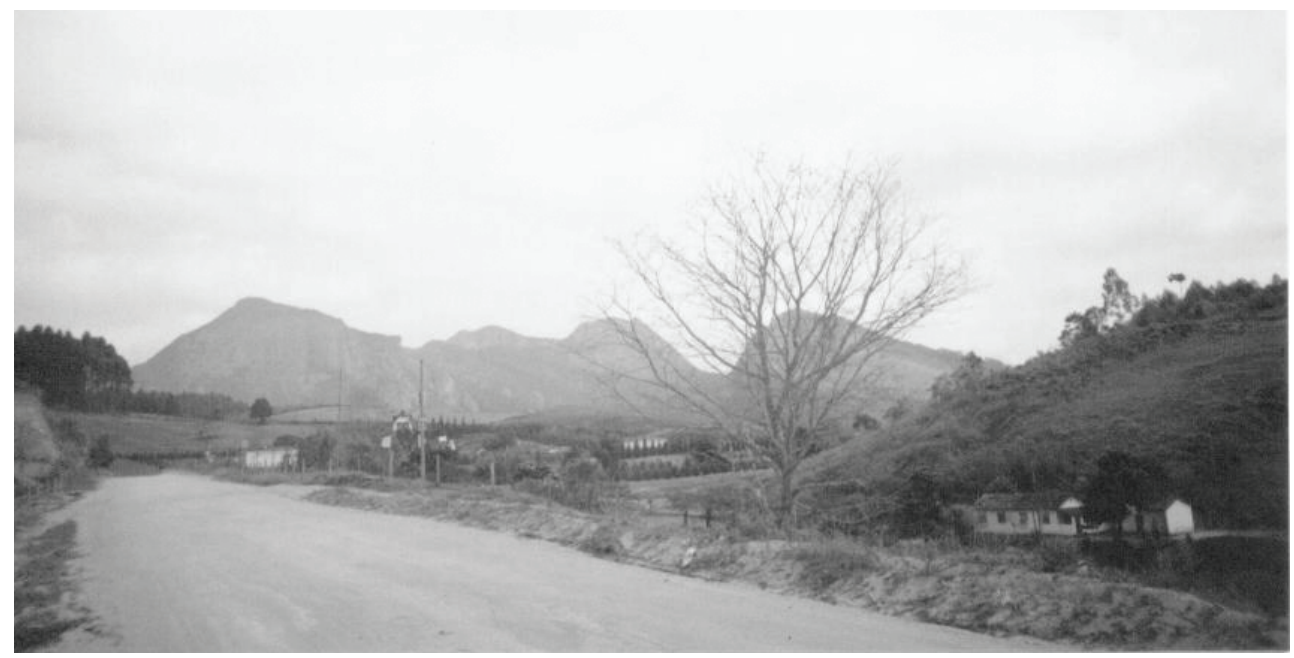

Fuente: Anderson Pereira Portuguez (2010).

${ }^{2}$ Instituto Brasileño de Geografía y Estadística. Órgano del Gobierno Federal responsable por la realización del censo demográfico. Disponible en http://www.ibge.gov.br/cidadesat/. Visitada el 26 de diciembre de 2011.

${ }^{3}$ Sigla oficial del Ayuntamiento Municipal de Santa María de Jetibá, utilizada para designarla en publicaciones y otras formas de documentos oficiales impresos y virtuales. 
Según Moraes (2004), basado en la clasificación de Köppen, los tipos climáticos que ocurren en la porción de la región serrana donde Santa María de Jetibá está situa$\mathrm{da}$, son $\mathrm{Cf}$ y $\mathrm{Cw}$, con variaciones entre $\mathrm{Cfa}$, Cfb y Cwa. Son tipos climáticos tropicales de característica meso térmica, con temperaturas superiores a $22^{\circ} \mathrm{C}$ en los días más calientes. En las áreas por encima de 650 metros de altitud, las mínimas pueden ser inferiores a $18^{\circ} \mathrm{C}$ en los días más fríos. La humedad relativa del aire es alta, entre $80 \%$ y $88 \%$, con promedios pluviométricos entre 1.000 y $1.500 \mathrm{~mm} /$ año.

Perrone y Moreira (2005) afirmaron que originalmente esas tierras eran recubiertas por extensos bosques tropicales que, a pesar de su heterogeneidad, recibieron el nombre genérico de Bosque Atlántico. Este sistema recubría el 86\% de la superficie del Estado y dominaba, en especial, la región serrana de Espírito Santo. Esta es una formación perennifolia, densa y con sub-bosques también densos. Los árboles poseen de 20 a 30 metros de altura con copas densas y troncos con diámetros variados. En las áreas más elevadas y con 2 a 3 meses secos, predominan las formaciones subperennifolias.

Imágenes de satélite estudiadas por Almeida Júnior (2006) muestran un alto grado de fragmentación de la vegetación. En campo, se pudo observar que los fragmentos ocurren, por lo general, en áreas donde existen diversos propietarios rurales, lo que indica que además del aspecto geográfico, los bosques remanentes son compartimentados por el sistema local de posesiones y derechos de uso.

Figura 3. Mapa Regeneración y deforestación totales - 1970-2005.

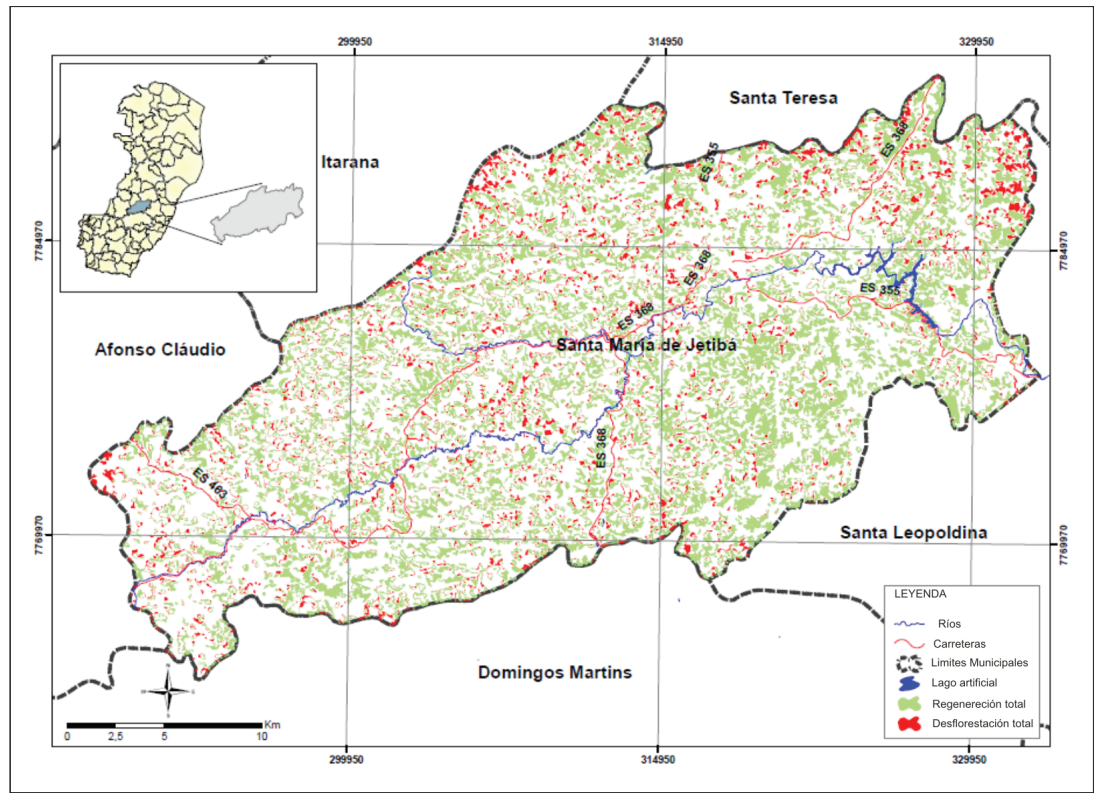

Fuente: Almeida Júnior (2006, p. 51). 
Con la pérdida de la cobertura vegetal, innumerables especies de la fauna nativa fueron perdidas y muchas otras se encuentran en riesgo de extinción. Según el Ayuntamiento Municipal de Santa María de Jetibá, se pueden todavía hoy encontrar algunos animales raros, sobre todo en las tierras más altas. Son monos, roedores, aves diversas, reptiles y hasta incluso aves migratorias. De esas especies, hay que destacar al mono muriqui (Brachyteles hypoxanthus), considerado el primate más grande del continente americano, con 1,2 m de altura (Portuguez, 2007).

La exuberancia natural de este sector del territorio estudiado ha atraído a turistas desde la década de 1970. Sin embargo, es actualmente que el sector recreativo y las actividades de contemplación se muestran realmente relevantes para la economía regional. Por este motivo la degradación creciente de los ecosistemas locales viene preocupando a empresarios y ambientalistas, que han unido sus esfuerzos junto al poder público para implementar acciones que promuevan el turismo sustentable, ya que se entiende que este modelo de uso es el más adecuado para asegurar calidad de vida a la población residente, al mismo tiempo que conserva los recursos paisajísticos de la región serrana de Espírito Santo.

La ocupación del espacio en Santa María de Jetibá siguió, a lo largo de su historia, algunas lógicas sobre las que hay que hacer algunas consideraciones. Desde el punto de vista ambiental, Santa María de Jetibá presenta procesos de degradación derivados del modelo de concesión de tierras para poblamiento, que el Gobierno Imperial ${ }^{4} \mathrm{im}$ plantó en el Sur de Brasil y en Espírito Santo a partir de la segunda década del siglo XIX.

En los Estados de Río de Janeiro y en São Paulo, los inmigrantes eran trabajadores asalariados, que no tenían acceso directo a la tierra. A su vez, en los Estados de Río Grande del Sur, en Santa Catarina, en Paraná y en Espírito Santo, las compañías de colonización promovían la expansión poblacional y la ocupación de tierras "devolutas", inclusive en precarias condiciones; aun a costa de la deforestación desenfrenada.

Desde el punto de vista económico, la región fue inicialmente incorporada a lo que Bittencourt (1989) llamó de zona de agricultura tropical de exportación, cuya base productiva a partir del siglo XIX fue la caficultura. Posteriormente, la ganadería, los criaderos y la horticultura pasaron a formar parte del paisaje municipal.

Desde el punto de vista cultural, los pomeranos que ocuparon la región impusieron sus formas culturales e iniciaron un proceso de relación con el ambiente basado en los principios culturales que trajeron de la región báltica. La arquitectura, el empedrado, la culinaria tradicional y principalmente la lengua ancestral, son ejemplos todavía vivos de la impresión en el paisaje, de los saberes y quehaceres tradicionales de sus habitantes (figs. 4 e 5 ).

\footnotetext{
${ }^{4}$ Oficialmente, Brasil fue el único país del continente americano que se constituyó como monarquía después de su independencia. El período imperial se extendió de 1822 a 1889.

${ }^{5}$ Tierras con florestas tropicales intocadas, que pertenecen al Estado y que son destinadas a la expansión de la ocupación agrícola.
} 
Figuras 4 y 5 . Arquitectura urbana y rural de tradición pomerana.
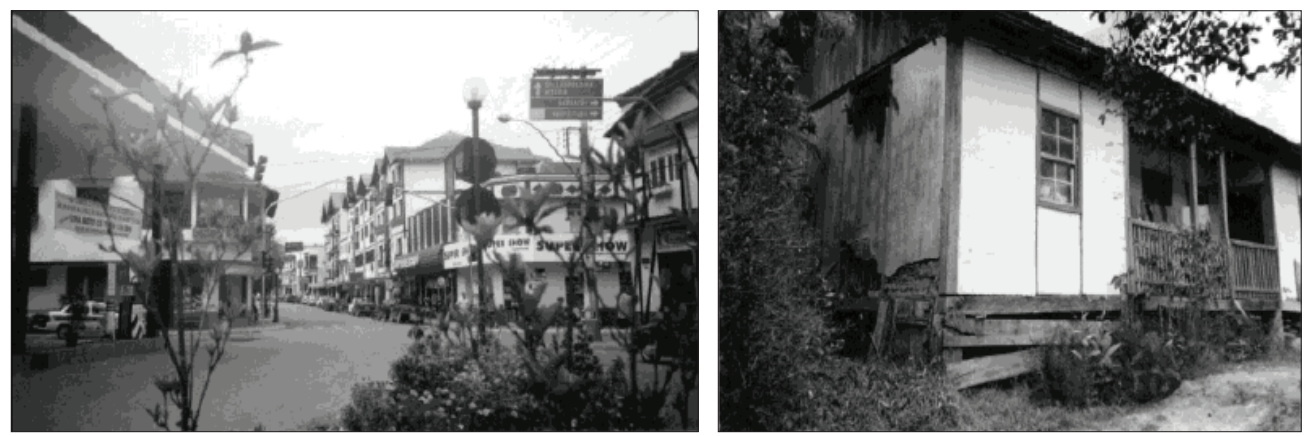

Fuente: Anderson Pereira Portuguez (2010).

Desde el punto de vista político (como desdoblamiento de lo cultural), Santa María de Jetibá se organizó a partir de sus características étnicas, religiosas y económicas. El municipio tuvo su constitución política iniciada con la Ley $n^{0} 3.913$, publicada en el Diario Oficial del Estado de Espírito Santo el día 23 de diciembre de 1986. La referida Ley dispone sobre el cambio de nombre del distrito de Jetibá, para Santa María de Jetibá. En aquella ocasión, el área citada pertenecía al municipio de Santa Leopoldina. Se desmembró con la publicación de la Ley 4.067, publicada en el Diario Oficial del Estado de Espírito Santo del 10 de mayo de 1988.

Administrativamente, el municipio de Santa María de Jetibá se divide oficialmente en 2 distritos: São João de Garrafão y el Distrito Sede. Sin embargo, según Portuguez (2007) las células político-territoriales son definidas por las parroquias luteranas. Alrededor de las iglesias, la vida se organiza y la comunidad mantiene sus lazos de cohesión y convivencia.

Vale la pena, en este momento, detallar un poco más los procesos históricos inherentes a la inmigración pomerana, pues la misma dio origen a una configuración geográfica única en escala nacional, haciendo de Santa María de Jetibá un refugio étnico de gran relevancia para el turismo cultural.

De acuerdo a Bittencourt (1987), la crisis agraria brasileña provocada por el fracaso del modelo lusitano que se basaba en los latifundios esclavizadores, hizo surgir una nueva situación social en el país y en particular en Espírito Santo a partir del siglo XIX. La gran propiedad necesitaba de mano de obra para trabajar en los cultivos de café, pero la escasez de esclavos hizo que el precio de la fuerza de trabajo encareciera la producción. Aliado a eso, la firma de leyes abolicionistas puso en jaque a la productividad de las grandes haciendas del valle del río Paraíba del Sur (entre los Estados de São Paulo y Río de Janeiro) y, de este modo, no sería Espírito Santo, tierra económicamente atrasada, quien se quedaría con los contingentes de trabajadores desplazados del noreste del país y de las áreas de explotación minera del Estado de Minas Gerais. 
Problemas sociales en Europa, sobre todo en las regiones que hoy llamamos de Alemania e Italia, favorecieron la política migratoria brasileña. Las crisis demográficas y las luchas campesinas establecidas durante la unificación alemana y la unificación italiana, crearon el suelo contextual para la expatriación de grandes levas de trabajadores de esos países. Las acciones norteamericanas de restricción a la inmigración durante la segunda mitad del siglo XIX también contribuyeron. A partir de la segunda década del siglo XIX, se inició la inmigración en masa, especialmente en los últimos 30 años de aquel siglo (Bittencourt, 1987).

La fase de gran expansión de la caficultura ocurrida a partir de la década de 1870 está, por lo tanto, íntimamente relacionada al gran flujo migratorio de labradores europeos. En 1872, cuando fue el primer re-censo realizado en Brasil, la población del Estado de Espírito Santo era de aproximadamente 82 mil habitantes. En 1900, este número saltó para 210 mil y en 1920, el Estado ya poseía 460 mil habitantes (Castiglioni y Reginato, 1997). Todo esto porque además del aporte poblacional acaecido con la inmigración, ocurrían también las migraciones intra-nacionales y el crecimiento vegetativo, en aquella época, era muy elevado. En el intervalo de apenas 48 años la población creció más de cinco veces.

En Espírito Santo, los italianos fueron los inmigrantes más numerosos, pero los germánicos fueron también muy representativos, sobre todo en la ocupación de la porción central de las sierras del Estado. En aquella época, la producción económica era muy tímida y la infraestructura muy precaria. Fueron los inmigrantes quienes recorrieron y exploraron las tierras, derrumbaron buena parte de los bosques, exterminaron brutalmente a los grupos indígenas remanentes y abrieron carreteras. Todo en nombre del progreso de la caficultura, que se convirtió en la base de las exportaciones estatales. La tabla 02, a continuación, presenta el volumen de entrada de inmigrantes europeos a Brasil entre 1880 y 1905.

Tabla 2. Entrada de extranjeros a Brasil 1880-1905.

\begin{tabular}{l|c|c|c|c|c}
\hline Año & Italianos & Germánicos & Austríacos & Españoles & Portugueses \\
\hline 1880 & 46.934 & 35.644 & 3.245 & 2.736 & 176.104 \\
\hline 1881 & 2.705 & 1.850 & 83 & 2.667 & 3.144 \\
\hline 1882 & 10.562 & 2.538 & 57 & 3.738 & 10.621 \\
\hline 1883 & 12.569 & 1.690 & 249 & 2.343 & 11.286 \\
\hline 1884 & 7.933 & 1.240 & 598 & 5.76 & 8.683 \\
\hline 1885 & 17.589 & 2.846 & 466 & 815 & 7.611 \\
\hline 1886 & 14.336 & 2.414 & 644 & 139 & 6.287 \\
\hline 1887 & 40.157 & 1.147 & 274 & 1.766 & 10.205 \\
\hline 1888 & 104.353 & 782 & 1.156 & 7.736 & 18.289 \\
\hline 1889 & 36.124 & 1.903 & 550 & 9.012 & 11.240 \\
\hline 1890 & 31.275 & 4.812 & 2.246 & 12.068 & 35.174 \\
\hline 1891 & 132.324 & 1.585 & 4.244 & 22.146 & 32.349 \\
\hline 1892 & 56.049 & 2.800 & 574 & 10.471 & 17.797 \\
\hline
\end{tabular}




\begin{tabular}{l|c|c|c|c|c}
\hline 1893 & 58.552 & 1.368 & 2.737 & 38.998 & 28.986 \\
\hline 1894 & 34.872 & 740 & 798 & 52.586 & 17.401 \\
\hline 1895 & 47.344 & 973 & 10.108 & 16.641 & 36.055 \\
\hline 1896 & 94.277 & 666 & 7.393 & 31.282 & 8.868 \\
\hline 1897 & 74.560 & 607 & 3.864 & 15.828 & 4.388 \\
\hline 1898 & 28.794 & 566 & 928 & 6.589 & 3.613 \\
\hline 1899 & 22.557 & 252 & 1.826 & 5.811 & 4.944 \\
\hline 1900 & 17.167 & 88 & 1.806 & 3.230 & 2.084 \\
\hline 1891 & 56.779 & 816 & 660 & 7.493 & 5.637 \\
\hline 1902 & 29.463 & 992 & 609 & 2.074 & 5.085 \\
\hline 1903 & 9.886 & 903 & 367 & 2.049 & 3.761 \\
\hline 1904 & 4.161 & 563 & 2136 & 4.780 & 2.060 \\
\hline 1905 & 3.468 & 192 & 138 & 3.115 & 14.120 \\
\hline Total & $\mathbf{9 9 4 . 7 9 0}$ & $\mathbf{6 9 9 7 7}$ & $\mathbf{4 5 8 3 3}$ & $\mathbf{2 6 6 . 6 8 9}$ & $\mathbf{4 8 5 . 7 9 2}$ \\
\hline
\end{tabular}

Fuente: Portuguez (2005, p. 23), basado en datos del acervo documental del Museo de la Inmigración Pomerana de Santa María de Jetibá.

Entendido este escenario, se puede pasar a detallar más específicamente la ocupación del área investigada. En 1847 un grupo de siete inmigrantes pomeranos llegó a Espírito Santo acompañando una leva de inmigrantes alemanes ${ }^{6}$. Entre 1858 y 1859 , llegaron algunas decenas más y la gran leva pomerana vino al Estado a bordo de los barcos Gutemberg, Anne Helene, Maria Heiden, Adolph, Doctor Barth y Hainan, entre los años 1872 y 1873 (Medeiros, 1997). Desembarcaron en Vitória (capital estatal) y fueron registrados 2.142 pomeranos, aunque algunos investigadores como Rogerio Medeiros, por ejemplo, creen que el número haya sido mayor.

Según Rölke (1996), Pomerania es un territorio actualmente ubicado entre Polonia y Alemania, cuya población quedó sin territorio en su casi totalidad entre 1850 y 1950. Migraron principalmente para el continente americano y en Brasil, se instalaron, sobre todo, en los Estados de Espírito Santo y Santa Catarina. En tierras espírito-santeses, se asentaron en ciudades como Santa María de Jetibá, Vila Pavão y Domingos Martins, mientras que en Santa Catarina, fundaron Pomerode, considerada la ciudad de arquitectura más germánica de Brasil.

En Pomerania, las familias ancestrales de estos grupos eran fundamentalmente labradoras (habitantes de la región de Hinterpommern) o pescadoras (principalmente los inmigrantes venidos de la región de Vorpommern, que vivían de los recursos del mar Báltico). La agricultura ya era difícil en aquellos tiempos, pues los suelos de Pomerania eran demasiado pobres y arenosos.

En Brasil, se convirtieron en labradores y recolectores de relativo éxito después de años de lucha para adaptarse a la nueva tierra (Medeiros, 1997). Instalados en la re-

${ }^{6}$ A pesar de que parte de Pomerania pertenece actualmente a Alemania, los descendientes de pomeranos de Espírito Santo insisten en no considerarse descendientes de alemanes. Afirman la identidad de su territorio de origen a pesar de no reivindicar más su independencia. 
gión serrana central de Espírito Santo, los inmigrantes alemanes y principalmente los pomeranos dejaron para las generaciones posteriores diversos rasgos culturales, que hoy ya no existen más en las tierras de origen, considerando los impactos que las dos grandes guerras provocaron en Europa. Las figuras 6 y 7 a continuación, muestran una tradición de identidad muy importante para las comunidades pomeranas y que está todavía presente en el Estado de Espírito Santo. Se trata del casamiento pomerano, en el cual la novia se viste de negro, con una faja verde en la cintura. Aunque los orígenes de esta práctica cultural sean controvertidos, popularmente se dice que esta tradición surgió como forma de protesta contra la exigencia de los señores feudales de ser los primeros en dormir con las novias, substituyendo a los maridos en la noche de nupcias.

Figuras 6 y 7. Novias vestidas de negro para la ceremonia de casamiento pomerano.
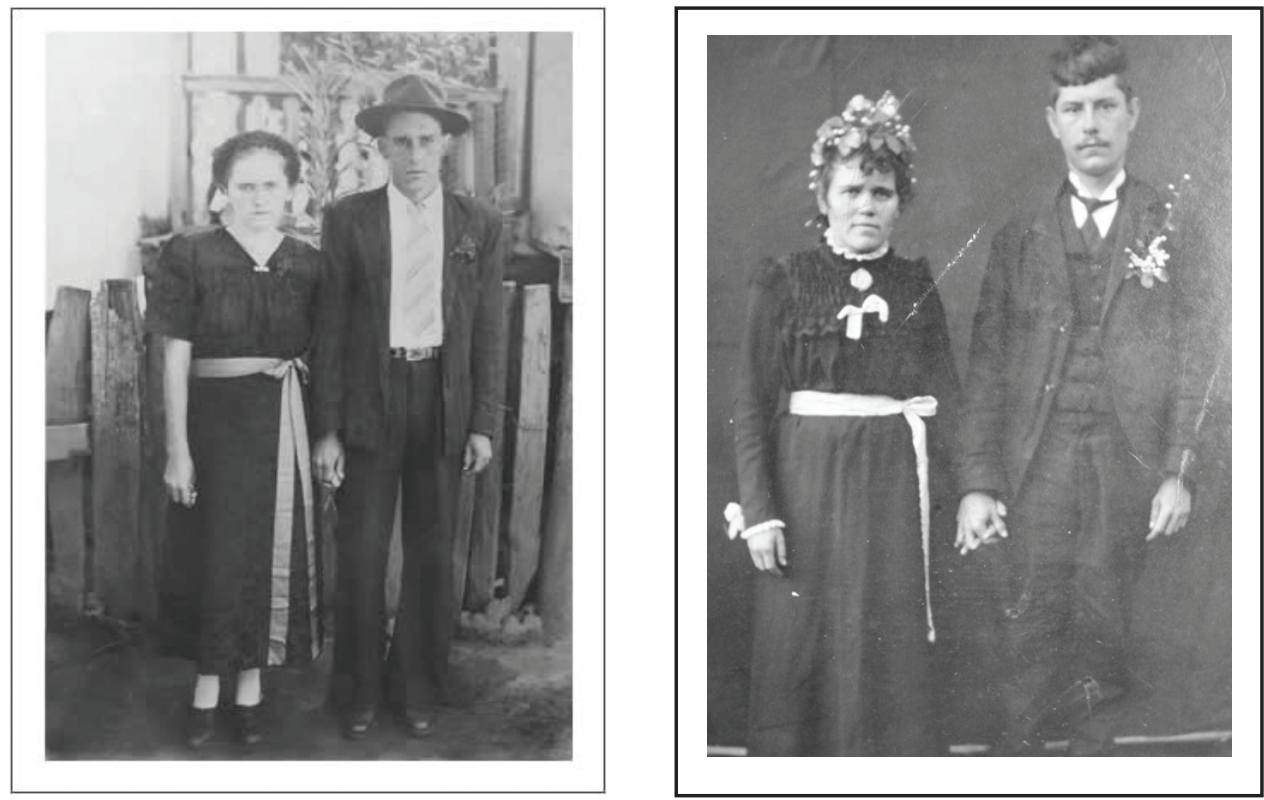

Fuentes: http://www.pomeranos.com.br/; http://www.pmsmj.es.gov.br/. Visitada el 26 de diciembre de 2011.

Las glebas demarcadas por el gobierno, sin embargo, no fueron suficientes para los colonos, que buscaron espontáneamente nuevas ocupaciones a fin de implementar una agricultura de mejor rendimiento $\mathrm{y}$, al mismo tiempo, asegurar tierras para sus hijos. Rölke (1996) recordó inclusive que los inmigrantes eran, además de labradores, artesanos. Se abastecían de buena parte de lo que necesitaban para sobrevivir, ya que hubo durante muchos años, claro abandono de algunas colonias por parte del poder público. 
Con el crecimiento de las áreas de inmigración, creció también la caficultura en todo el Estado. Variaciones de tipos de café fueron introducidas a lo largo del tiempo $\mathrm{y}$, de este modo, la producción se mostró creciente y substituidora de los bosques originales. También prevalecieron las pequeñas y medias propiedades, figurando Espírito Santo entre los Estados de estructura agraria menos concentrada, a pesar de que las desigualdades en lo que se refiere al acceso a la tierra sea una característica del Brasil actual. El Estado no escapa a la regla. En algunos puntos aislados, las luchas por la reforma agraria es un hecho social distintivo.

La historia de los pueblos europeos que migraron para Espírito Santo, así como las actividades cotidianas de sus descendientes explican en gran parte la configuración geográfica del interior de este Estado. Son las peculiaridades arquitectónicas, las tradiciones orales, las festividades, la religiosidad y otros aspectos culturales, que han justificado el viaje de muchos turistas a este sector, donde los pueblos y ciudades cuentan diferentes contextos del pasado, en medio de paisajes muy atractivos desde el punto de vista escénico. Santa María de Jetibá es realmente una unidad diferenciada de la región serrana, debido al alto grado de conservación de las tradiciones pomeranas, lo que no ocurrió en muchos otros municipios.

\section{USOS PRODUCTIVOS Y LACUESTIÓN DE LASUSTENTABILIDAD RURAL}

El diagnóstico rural realizado en el municipio de Santa María de Jetibá para la elaboración del presente trabajo, se enfocó en dos aspectos más específicos: los usos productivos (funcionalidades del paisaje) y el tipo de manejo que los propietarios tienen de los recursos naturales, sobre todo del agua.

En el municipio investigado, predominan las propiedades de pequeño y mediano porte, no habiendo sido identificado ningún latifundio. La mayor parte de las unidades visitadas posee hasta 50 hectáreas $(76 \%)$, de modo que no se verificó el fenómeno de la concentración de tierras, tan común en otros Estados brasileños, donde la agricultura tropical de exportación también es un hecho. Estas características colocan a Santa María de Jetibá en el rol de los municipios brasileños donde predomina la agricultura familiar.

La propia historia de la inmigración proporcionó esta característica agraria, ya que las familias extranjeras recibían unidades pequeñas para el cultivo de las compañías de inmigración. La heredad también colaboró con la definición de la actual estructura agraria, ya que las familias de inmigrantes eran consideradas fecundas y al morir, el patriarca dejaba gran número de herederos. Este hecho fragmentó aún más el paisaje rural. Esto se reflejó en otro dato recogido: el origen étnico de los productores. En las áreas visitadas, el 100\% de los propietarios son de origen germánico, de los cuales el $94,1 \%$ se declararon descendientes de pomeranos.

No en todas las propiedades poseen planta topográfica. En la época de la realización de las entrevistas, el 58,82\% posee documentación de registro y la planta, mientras que el $41,18 \%$ de los productores interrogados afirmaron que no habían conseguido la documentación completa, a pesar de poseer documentos que comprueban la 
posesión del terreno. Sin embargo, se debe resaltar que el Gobierno Federal ha creado diversos incentivos para la regularización de la propiedad familiar. De esta forma, estos datos están sufriendo alteraciones constantes, con tendencia a la ampliación de los registros inmobiliarios rurales.

De acuerdo a Portuguez (2005), en el pasado, muchos descendientes de inmigrantes perdieron sus propiedades con personas que venían de Vitória con documentos falsos declarando posesión legal. En algunos casos, al intentar registrar la propiedad y legalizar la posesión, eran llevados a firmar documentos cuyo contenido les era desconocido, pues esos inmigrantes y sus primeros descendientes no conocían con profundidad la lengua portuguesa. El hecho es que ese sistema de golpes generó profunda desconfianza con relación a los registros civiles y/o personas de fuera de la comunidad. Inclusive hoy, resquicios de ese recelo están presentes en la relación de los agricultores con visitantes?

Infelizmente, este hecho ha generado fuerte impacto sobre la actividad turística, pues muchos propietarios no se han sentido cómodos con la presencia de extraños en sus haciendas y fincas. Desde niños, se acostumbraron a oír de sus padres que "el pueblo de la capital no es gente confiable". Esta frase se convirtió en un dicho popular y fue oída durante las actividades de campo en diversas ocasiones.

Otra cuestión que puede ser mencionada es la alta concentración poblacional en el medio rural. De los casi 34.176 habitantes de Santa María de Jetibá, cerca del 65,48\% viven en la zona rural. Según Portuguez (2007), esto ayuda a que el contenido de ruralidad desborde hacia dentro del espacio urbano, de forma que en la ciudad, se puede observar muy fácilmente como la agricultura, la ganadería y la producción de granja son importantes rasgos definidores de la identidad socio-espacial en escala local. El comercio de implementos agrícolas, las casas de productos veterinarios, las cooperativas y sindicatos rurales, la comercialización de productos cultivados en el municipio, las fiestas urbanas, en fin, son ejemplos de expresiones de este desbordamiento, que evidentemente es contradictorio y complejo.

Es contradictorio porque la lógica urbana también se expresa en el medio rural. Este fenómeno es siempre controvertido en ciudades pequeñas como Santa María de Jetibá. Si por un lado buena parte del comercio se vuelca a los intereses de los propietarios, por otro, los implementos agrícolas son producidos en grandes parques industriales urbanos. Entre 2005 y 2010, período en el cual se realizó este y otros estudios en el municipio, se notó claramente el creciente abandono del transporte que usa la fuerza animal (caballos, burros y mulas), por la utilización de motocicletas, que actualmente, son muy baratas en Brasil.

A pesar de esta alteración que es simbólica y significativa, la mecanización es muy precaria en áreas de agricultura familiar, como Santa María de Jetibá. El trabajo animal y la forma familiar son las bases del proceso productivo, aunque los micro-

${ }^{7}$ Durante la recogida de testimonios en campo, muchas familias se encerraban en casa al ver el coche aproximándose a la propiedad. Fue necesario contratar a una habitante local para servir de traductora, para explicar nuestras intenciones a cada entrevistado en lengua ancestral. Observamos que los habitantes del medio rural con más de 50 años se comunican casi únicamente en pomerano y muchos no hablan portugués, a pesar de ser brasileños de la tercera generación. 
tractores y las motocicletas estén popularizándose cada vez más debido al bajo costo. Los micro-tractores fueron encontrados en el $70 \%$ de las propiedades investigadas. Sin embargo, estas máquinas no llegan a romper las tradiciones muy bien sedimentadas del trabajo en familia.

En otras palabras, se puede decir que la ciudad se presenta mucho más vinculada a la economía local/regional, que al contenido de globalidad que es típico de los espacios urbanos, aunque estos también existan. Por lo tanto, se vuelve prioritario mantener el medio rural en condiciones productivas adecuadas y sustentables, pues la dinámica social local de cierta forma se relaciona a él.

En relación a la producción, se observó que el $64,7 \%$ de las propiedades presentan hasta el 30\% de su superficie ocupada con las más diversificadas actividades agrícolas, sin detectar en el universo investigado ninguna unidad que se dedicara a la ganadería. En cuanto al elenco de tipos de cultivo, se buscó identificar en las unidades visitadas las actividades principales y las de importancia secundaria. En orden, se destacan la horticultura, la caficultura y las plantaciones de cereales. De los cultivos secundarios, se destacan el frijol (judía), el ajo, la cebolla, el eucalipto (para la industria maderera y de celulosa) y otros.

La caficultura aún ocupa papel de importancia en la economía local, siendo practicada en el $62 \%$ de las unidades visitadas. Es evidente que las fuerzas actuales del mercado internacional del café son en gran parte responsables del mantenimiento del cultivo cafetero, aunque no se puede ignorar el papel histórico de esta actividad en el municipio y en el propio asentamiento de los primeros colonos en la región serrana del Estado de Espírito Santo.

En las áreas investigadas, se observó que los agricultores han desarrollado plantaciones colocando los plantones en canteros horizontales, inclusive en laderas escarpadas, con una técnica que se parece a la de la curva de nivel, pero que trae rasgos de las antiguas plantaciones de sus ancestrales. El espaciamiento es mucho más una actitud a favor de la comodidad a la hora de la cosecha que de la propia tecnología de plantación. Como se verifica en la fig. 8, el resultado, en algunos casos, es la aceleración de los procesos erosivos.

Figura 8. Pérdida de suelo en áreas de cultivo de café.

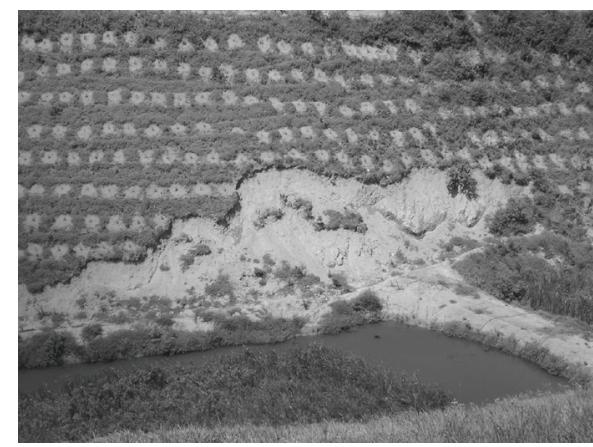

Fuente: Anderson Pereira Portuguez (2010). 
Aunque la ganadería no ha sido apuntada como actividad relevante en las propiedades visitadas, se observó que en algunas localidades se pueden encontrar pequeños pastos y áreas destinadas al confinamiento de los ganados bovino y porcino.

Finalmente, vale la pena destacar el peso económico de las granjas en la economía de Santa María de Jetibá, que es uno de los mayores centros de avicultura del país posicionándose entre las cinco ciudades brasileñas en producción de huevos. En las áreas visitadas para la recogida de datos, aunque la avicultura sea importante, solo dos propiedades fueron sorteadas para componer la muestra que dio origen a la presente investigación ( $7 \%$ del total). Los propietarios presentaron a la producción de granja como un complemento de renta, sin ser esta actividad la predominante. Por este motivo, no cabe una caracterización detallada de la avicultura local. Sin embargo, no se la puede ignorar, pues en diversos puntos del paisaje rural del municipio, se pudo visualizar la presencia de grandes unidades productoras (fig. 9).

Figura 9. Galpones de avicultura en Santa María de Jetibá.

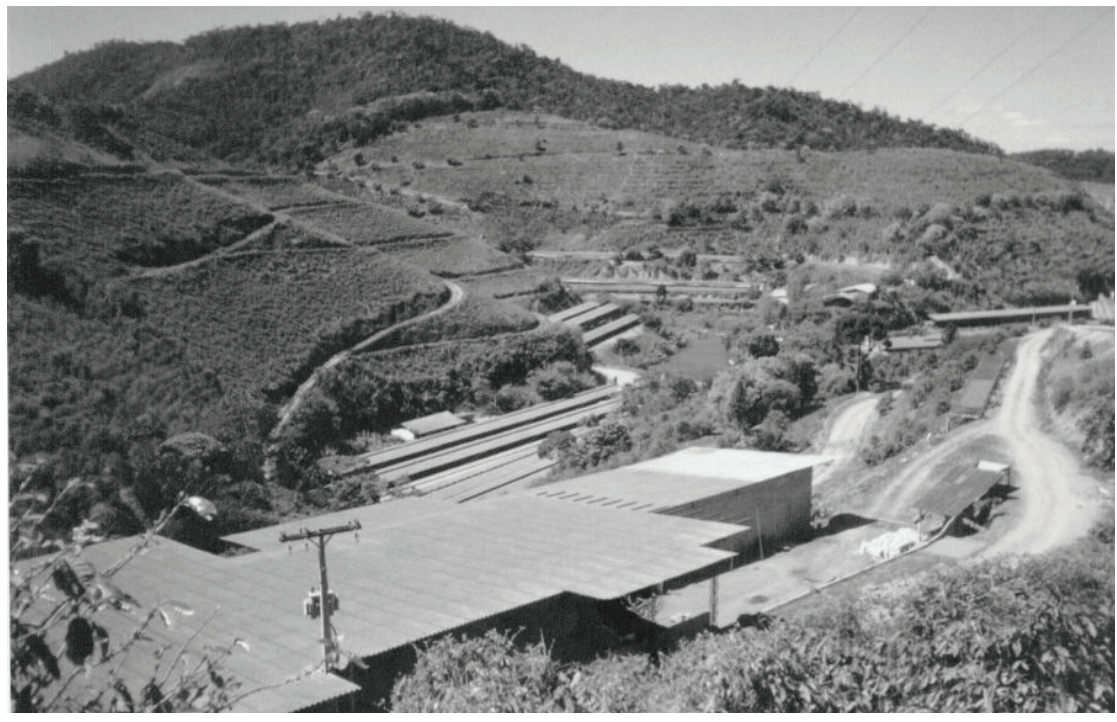

Fuente: Anderson Pereira Portuguez (2010).

Las granjas garantizan proyección económica para Santa María de Jetibá, que realiza una de las mayores ferias del sector: la Fenaovo, que reúne productores, proveedores y clientes en los espacios de eventos de la ciudad. Vale destacar que en una de las áreas visitadas, Río de las Pedras, se constató la presencia de criaderos de pollos caipiras $^{8}$

${ }^{8}$ Pollo común, mestizo, que tiene la carne más dura, huesos rígidos e cartilágines menos desarrollados. 
en sistema de confinamiento. Estas aves alcanzan valores muy rentables en el mercado metropolitano.

Además de los pollos de granja y los pollos caipiras, las codornices, los patos y los pavos también aseguran buena rentabilidad para las empresas rurales de la ciudad, a pesar de que estos últimos sean criaderos más raros.

\subsection{SALUD AMBIENTAL RURAL: UN TEMA POLÉMICO EN UNA REALIDAD CONTRADICTORIA}

Uno de los aspectos que se buscó observar en campo fue el agregado de técnicas de cultivo, sobre todo por medio de la adquisición de innovaciones tecnológicas, maquinarias y uso de productos químicos en los cultivos.

Se vio que los productores de las comunidades investigadas pueden ser considerados tradicionales en relación a las innovaciones administrativas, pues cuidan de la propiedad a partir de principios poco innovadores, muchos con quejas en relación a endeudamientos y baja capacidad de inversión.

La producción aún es predominantemente familiar, con poca utilización de mano de obra contratada, en los moldes de la agricultura campesina que caracteriza a ambientes de resistencia cultural, como es el caso de Santa María de Jetibá. En algunas localidades, como Río Possmoser y Alto Santa María, todavía se producen cestas artesanales para acomodar el ajo, lo que indica la sobrevivencia de prácticas artesanales en los hábitos de cultivo y manejo de la producción.

En campo, se observó que el agregado de recursos tecnológicos al proceso agrícola se da en forma bien lenta y heterogénea, de acuerdo al poder adquisitivo de las familias productoras. Por lo general, la presencia tecnológica se da por medio de la irrigación, de la utilización de productos químicos y algunas sugerencias de técnicos de órganos de fomento y orientación a la producción rural.

Se averiguó que el $53 \%$ de los productores utilizan comúnmente productos de diversas industrias químicas, con funciones variadas (herbicidas, pesticidas y abonos). Declararon buscar orientaciones técnicas antes de la adquisición de los mismos y que siguen las recomendaciones de uso. Sin embargo, se observó una clara ausencia de estandarización en el manejo de productos considerados peligrosos.

El tomate es el producto de la horticultura que más recibe aplicaciones de defensivos agrícolas. Según reportajes siempre recurrentes de la prensa regional, existe todavía aplicación en gran escala en pimientos y frutillas.

Según los propietarios, los técnicos agrícolas, cuando son llamados, realizan generalmente una única visita durante la cual enseñan a usar los productos químicos. En años posteriores, juzgando que ya conocen las peculiaridades de los productos, los agricultores prescinden de la presencia del especialista y pasan a comprar y aplicar los defensivos por cuenta y riesgo propios. Es bueno recordar que estamos hablando de una población que aún hoy enfrenta dificultades con la lengua portuguesa y debido al hecho de que el pomerano es un dialecto transmitido socialmente por medio de la oralidad (no posee sistematización lingüística), no es posible redactar prospectos y recetarios en la lengua ancestral. 
Al ser interrogados sobre el manejo y las precauciones antes, durante y después de la aplicación de los agrotóxicos, los productores en un primer momento afirmaron que utilizan máscaras, aplicadores, botas y guantes. Sin embargo, la convivencia de siete años con los productores mostró que esto es verdad tan solo en parte. Todavía falta mucha orientación técnica para un adecuado manejo de estos productos en los cultivos.

Algunas familias poseen miembros con graves problemas de salud como consecuencia de un largo historial de uso abusivo de agrotóxicos. En campo, se entrevistó una señora perteneciente a la familia Brandt que, con lágrimas, afirmó que sufre constantemente de crisis depresivas y que no consigue tratamiento médico adecuado. Afirmó también que por desconocimiento, pulverizó la plantación con productos peligrosos hasta los últimos días de embarazo y que después de la muerte prematura del hijo, comenzó a tener problemas neurológicos en función de los hechos y de la propia contaminación que sufrió.

Santa María de Jetibá detenta uno de los mayores índices de suicidio en todo Brasil y hay fuertes indicios de relación entre el uso abusivo de agrotóxicos y las enfermedades de las familias agricultoras ${ }^{9}$. Los agrotóxicos más utilizados son, según los entrevistados, los organofosforados, carbamatos y glifosatos.

Los casos más graves de disturbios neurológicos llevan ocasionalmente el enfermo a intentar suicidio, o efectivamente suicidar-se. Según Macente et al. (2009), que estudiaron este fenómeno en este municipio entre 2001 y 2007, la mayor parte de los suicidios y tentativas de suicidios ocurren entre hombres $(69,4 \%)$. El grupo etario crítico (para hombres y mujeres) es el de 25 a 35 años. Finalmente, entre los diversos y aterrorizantes datos levantados por las autoras, la utilización de agrotóxicos como forma deliberada de envenenamiento fue responsable por el 7,1\% de los suicidios y por el $42,5 \%$ de las tentativas.

Frente a esta triste realidad, las autoridades municipales están incentivando modelos de agricultura que no hacen uso de agrotóxicos. Hay un volumen considerable de agricultores que utilizan productos de origen orgánico (29\%). Por lo general, es estiércol de bovinos y de pollos, ya que las granjas son fuente abundante de materia orgánica en el municipio. Además de bajar los costos de la producción, esta actitud concuerda con los nuevos intereses de consumo de la clase media de la Región Metropolitana de la Gran Vitória, que ha valorizado la agricultura orgánica, considerada más sana.

Inclusive el control de plagas y enfermedades se hace con productos de origen no industrial en algunas propiedades, que han buscado algunas certificaciones de calidad, como el sello orgánico otorgado por la Asociación de Certificación de Productos Orgánicos de Espírito Santo - CHÃO VIVO.

${ }^{9}$ Depresión como consecuencia de disturbios neurológicos; aumento de la sensibilidad al alcohol (lo que resulta en agravamiento del alcoholismo); riesgo de cáncer; malformación congénita; enfermedades respiratorias y en la piel; alteraciones en la inmunidad y en la dinámica hormonal. 
Figura 10. Hortalizas cultivadas de forma sustentable en Santa María de Jetibá.

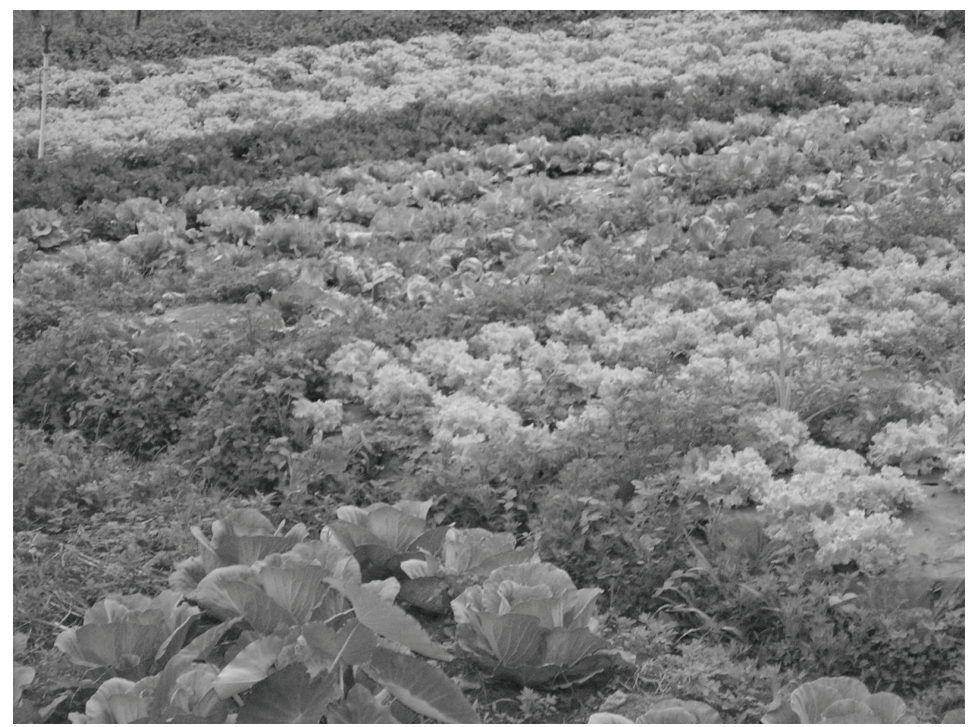

Fuente: Anderson Pereira Portuguez (2010).

Las propiedades de cultivo orgánico han ganado notoriedad en los medios de comunicación estatal y, en función de esto, muchos restaurantes y habitantes de la Gran Vitória han optado por realizar sus compras de verduras y legumbres directamente en estas propiedades, lo que fortalece el agroturismo local. En contrapartida, es cierto que las familias agricultoras han encontrado algunas dificultades técnicas y financieras para la implantación de la agricultura orgánica.

\subsection{USO DEL AGUA Y LA EXPERIENCIA AMBIENTAL DE LOS SUJETOS SOCIALES LOCALES}

En las propiedades visitadas, el uso del agua reveló otros aspectos del modelo productivo y del dinamismo rural de Santa María de Jetibá. El municipio es cuna de uno de los ríos más importantes del Estado: el río Santa María de la Vitória. Este río y sus afluentes han servido al municipio de diversas formas: abastecimiento de agua, desedentación de animales, irrigación, generación de energía eléctrica, entre otras.

El análisis de los datos referentes a la utilización del agua en la zona rural mostró que las nacientes son las fuentes preferidas de captación, siendo responsables por el abastecimiento directo del 94,1\% de los domicilios visitados. Donde el agua de las nacientes no es captada directamente para las cajas de agua (5,9\% de las propiedades visitadas), ocurre el abastecimiento de pozos y, desde ellos, el agua es bombeada hasta las casas. 
Cuando fueron interrogados sobre el destino del agua utilizada, se observó que el uso de fosas es la medida preferida entre los productores, por ser una alternativa barata y de fácil ejecución.

Las nacientes son además utilizadas para la desedentación de animales y, en algunos casos, para la irrigación de los cultivos. Las propiedades que bombean agua a tanques, generalmente hacen la captación en nacientes o ríos y el almacenamiento se da en gran cantidad en los pozos para utilización posterior. El contenido de los pozos artesianos, a su vez, se presta al uso doméstico.

La irrigación es una práctica que fue verificada en el 94\% de las propiedades visitadas y en ellas, se pudo constatar que el único sistema adoptado por los agricultores fue el de aspersión. Prácticas agrícolas con modelos más ecológicos de irrigación, como el sistema de goteo (irrigación localizada), son consideradas caras por los productores, que consideran a los aspersores más eficientes y baratos.

La captación es realizada con motobombas de capacidades diversas. Solamente un propietario sabía informar el flujo del equipo. Los demás afirmaron que desconocen o que nunca se preocuparon en saber esa información. La adquisición de las motobombas se da en la medida en que los aspersores son adquiridos y necesitan de alimentación.

En cuanto al horario de riego, se notó que los propietarios necesitan orientaciones en relación al mejor horario para efectuarlo. La irrigación es realizada por la mañana y al final de la tarde, cuando el suelo está caliente por el calor del sol, hecho que reduce la optimización del uso del agua. La re-evaporación inmediatamente después de la irrigación pudo ser vista con facilidad durante el período vespertino e incluso así, los productores no se dieron cuenta del desperdicio hídrico.

En este momento es válido recordar que las aguas superficiales son atractivos turísticos importantes, destacándose las innumerables cascadas existentes en el municipio, así como la histórica represa de Río Bonito, considerada el lago artificial de mejor impresión escénica del Estado. La protección de las nacientes es, por lo tanto, un factor relevante para la sustentabilidad del turismo local.

Figuras 11 y 12. Cascada y usina hidroeléctrica: atractivos turísticos de Santa María de Jetibá.
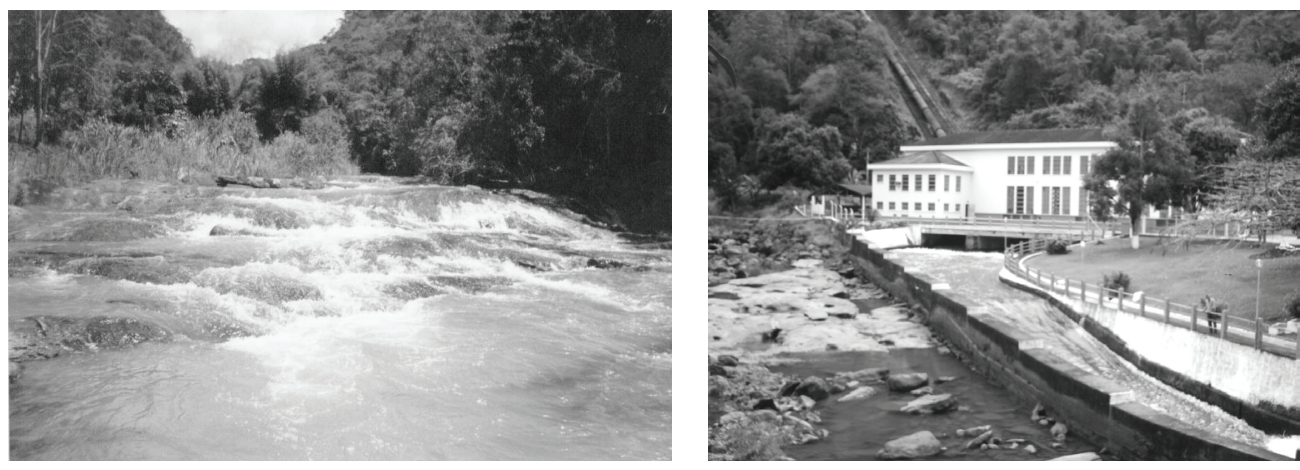

Fuente: Anderson Pereira Portuguez (2010). 
Durante las entrevistas realizadas en campo, los productores con más de 50 años de edad demostraron una cierta nostalgia de los tiempos en que la región era recubierta por el denso bosque y recordaron que ellos, aún niños, jugaban con los animales en la entrada del bosque ${ }^{10}$. La Sra. Shimidt, por ejemplo, contó que en el pasado los monos muriquis ${ }^{11}$ eran más comunes y que aparecían tanto como los monos barbados ${ }^{12}$ : "hoy casi no hay más monos, pero cuando uno comenzó, ellos corrían por la orilla del camino y nos arrojaban pedazos de tronco".

Fueron muchas las declaraciones interesadas en conservar la naturaleza. En líneas generales, se puede decir que incluso los productores analfabetos se mostraron sensibles en relación a la necesidad de proteger los recursos naturales locales, pues sus familias fueron testigos oculares de una serie de transformaciones que se sucedieron a lo largo de las últimas décadas: nacientes se secaron, arroyos que antes eran de flujo abundante hoy en día solo aparecen en período de lluvias, agradación del río Santa María de la Vitória, desaparición de orquídeas y muchos otros eventos.

Lo que se percibió, es que la necesidad de sobrevivencia impuso acciones que ellos reconocieron ser dañinas para la naturaleza, pero que en la época en que fueron creadas, eran comunes y no pasaban por los controles rigurosos de la actualidad. El propio uso de agrotóxicos puede ser citado como ejemplo. A pesar de sentirse profundamente vinculados a la tierra y a la naturaleza y sacar de ellas directamente buena parte de su sustento, los descendientes de pomeranos lamentaron, en diversos testimonios, no haber sabido antes de acciones de cultivo que hoy son triviales, pero que en el pasado eran desconocidas y, por ese motivo, degradaban el medio ambiente, aunque sin esa intención.

El bosque nativo, a pesar de fragmentado, aún se encuentra presente en muchas de las propiedades visitadas. El 64\% de las haciendas poseen hasta 20 hectáreas de bosques nativos y/o trechos en fase de recuperación, mientras que el $12 \%$ presenta entre el $20 \%$ y $40 \%$ de superficie forestada. A pesar de la discontinuidad fitofisiográfica, este volumen es expresivo, ya que los monos muriquis (ejemplo de especie rara de la fauna local) son ocasionalmente vistos por los productores en todas las unidades investigadas.

Se observó además que el área destinada al cultivo está siendo realmente utilizada y, por este motivo, las acciones de reforestación son tímidas. El propietario Sr. Seick (de São Sebastião de Belém) afirmó: "Llegué a plantar unos quinientos pinos, pero no prosperaron. Ellos murieron". A su vez, el Sr. Berger (de la localidad de Ilha Berger) declaró que eligió el eucalipto como especie para ser utilizada en la recomposición de bosques, pero que todavía está estudiando las áreas de la propiedad que van a ser destinadas a esa plantación. Al ser visitado, el propietario Sr. Boldt (de la comunidad Río de las Pedras) informó tener interés en ayuda técnica, pues según él, hay áreas en la hacienda que podrían ser reforestadas, pero que carece de seguimiento especializado.

\footnotetext{
${ }^{10}$ Se refiere a las áreas del bosque nativo cerca de las carreteras, donde los senderos naturales eran frecuentados por los niños durante sus juegos y paseos buscando frutos.

${ }^{11}$ Brachyteles hypoxanthus.

${ }^{12}$ Alouatta guariba.
} 
Al ser interrogados sobre las principales acciones de preservación que emprenden para conservar los bosques remanentes, algunos productores afirmaron que evitan incluso hasta entrar en el bosque. Según los informantes, las acciones que toman por iniciativa propia para evitar la degradación de la vegetación y de la fauna que protege son: impiden la caza; evitan quemas, mantienen a los bosques remanentes y algunos hasta hacen reforestación.

Según los productores rurales interrogados, existen en los bosques locales una serie de animales silvestres, que componen un conjunto variado de la fauna nativa, a pesar de la gran fragmentación de los bosques remanentes. Son mamíferos de pequeño y medio porte, pequeños lagartos, serpientes, aves diversas, y otros. De todas las especies locales, las de primates son las que más llaman la atención, tanto por el porte de los monos, como por el aspecto turístico asociado a ellos. Como ejemplo, se puede citar la designación del mono muriqui como principal candidato al puesto de mascota de las Olimpíadas de 2016 en Río de Janeiro. Hay senderos en Santa María de Jetibá específicos para la observación de estos animales en medio del Bosque Atlántico.

Ninguno de los 17 productores entrevistados declaró cazar o permitir la caza. Sin embargo, una práctica común entre los productores rurales es la cría de mascotas como perros y gatos, que ocasionalmente pueden cazar y sacrificar pequeños roedores, crías de mamíferos, aves y otros. En campo, además de constatarse una población numerosa de mascotas, se observó también que algunos perros son agresivos, curiosos y potencialmente peligrosos para la fauna nativa. El $88 \%$ de los propietarios posee mascotas con instinto cazador, a pesar de que sus dueños declaren que se tratan de individuos dóciles. Sin embargo, el 53\% de los entrevistados desconocen las actividades de sus animales, porque no permanecen en el emplazamiento de las haciendas por mucho tiempo durante el período normal de trabajo en el campo.

\section{CONCLUSIONES}

El diagnóstico rural realizado en el municipio de Santa María de Jetibá (Estado de Espírito Santo - Brasil), presentó una serie de consecuencias indeseables de una larga trayectoria de degradación ambiental iniciada en el siglo XIX, cuando los primeros grupos de inmigrantes germánicos se instalaron a lo largo del río Santa María de la Vitória.

La caficultura fue la actividad responsable por la fuerte fragmentación del bosque tropical, donde viven especies actualmente amenazadas de extinción. Incluso con la diversificación económica ocurrida en la segunda mitad del siglo XX, los recursos naturales locales continuaron siendo apropiados de forma inadecuada, tanto por desconocimiento de técnicas sustentables de producción, como por negligencia de los órganos de gobierno responsables por atender a las familias productoras.

Entre los grandes problemas ambientales derivados de las prácticas productivas, se destaca para el tiempo actual, el uso inadecuado de productos químicos como: pesticidas, fertilizantes y herbicidas, que además de contaminar la producción, han generado problemas de salud entre las familias productoras, como casos de cáncer y 
disturbios neurológicos. Se están realizando investigaciones para comprobar que el elevadísimo índice de suicidios en el municipio, resulta en larga escala de los problemas emocionales y mentales causados por el envenenamiento voluntario e involuntario de los trabajadores rurales.

La productividad rural se asienta principalmente en la pequeña propiedad familiar y las producciones cafetera, hortícola y de granja son las más importantes. Aunque el municipio sea una de las cinco ciudades brasileñas con mayor producción de huevos, la población muestra de esta investigación sobrevive predominantemente de plantaciones de café y de hortalizas.

Se observó, finalmente, que las comunidades rurales necesitan orientaciones técnicas para un mejor manejo de los recursos naturales que disponen. Para ello, se propone:

-Que se intensifiquen las acciones de extensión rural en el municipio, como forma de reducir la utilización inadecuada de agrotóxicos y, al mismo tiempo, que se incentive la adopción de técnicas más sustentables de cultivo, como la agricultura orgánica;

-Es necesario apoyar las acciones individuales y colectivas de reforestación. Se observó la existencia de productores realmente preocupados con la cuestión ambiental en escala local, pero sin la debida orientación para la recomposición de la vegetación de partes de sus propiedades.

-Se recomienda una mayor atención del ayuntamiento en relación a la salud ambiental rural. Son aterrorizantes los índices de suicidio, cáncer y envenenamiento (voluntario e involuntario) por agrotóxico en el municipio.

-Se sugiere un estudio más profundo sobre la apropiación de los recursos hídricos, pues el manejo en las propiedades se da directamente en las nacientes de los tributarios del río Santa María de la Vitória. Esto puede causar graves problemas a largo plazo.

-Son necesarias actividades de educación ambiental, tanto para incentivar prácticas más sustentables, como para recuperar aunque fuera en parte, la biodiversidad local. Una atención especial debe ser dada a las propiedades portadoras de bosques con presencia de especies amenazadas de extinción, como el mono muriqui, por ejemplo.

-Para las áreas deforestadas, destinadas al cultivo cafetero, se propone la adopción de técnicas de cultivo que eviten la pérdida de suelo por procesos erosivos.

-Que se incentive el turismo ecológico, como forma de agregar renta a las propiedades interesadas y como estrategia de educación ambiental. Se cree que el contacto con la naturaleza puede incentivar actitudes que condigan más con las necesidades de la naturaleza y producción rural.

- Finalmente, se propone que nuevos estudios sean realizados en Santa María de Jetibá, sobre todo sobre dos temas más urgentes detectados en esta investigación. En primer lugar, que se discutan alternativas para la creación de corredores de vegetación que interconecten los fragmentos forestales remanentes del Bosque Atlántico. De esta forma, la fauna y la flora podrán promover los necesarios cambios genéticos que aseguran la saludable perpetuación de las especies. En segundo lugar, es el momento de debatir técnicas sustentables e innovadoras más adecuadas para el perfil productivo local, que se amolden a las peculiaridades culturales de las comunidades pomeranas. 


\section{BIBLIOGRAFÍA}

ALMEIDA JÚNIOR, H. C. (2006). Evolução da fragmentação de mata no município de Santa Maria de Jetibá. Vitória, Universidade Federal do Espírito Santo.

BITTENCOURT, G. (1987). Café e modernização: o Espirito Santo no século XIX. Rio de Janeiro, Cátedra.

BITTENCOURT, G. (1989). Notícias do Espírito Santo. Rio de Janeiro, Cátedra.

BOLDT, M.O casamento pomerano. Disponível em http://www.acurbe.org.br/

portal/ver_artigo. Acessado em 26 de dezembro de 2011.

CASTIGLIONI, A. H. E.; REGINATO, M. (1997). Imigração italiana no Espírito Santo: o banco de dados. Vitória, Universidade Federal do Espírito Santo/Università degli Studi di Torino.

HEINEMANN, J. C. Casamento Pomerano. Disponível em: http://www.pomeranos. com.br/ Acessado em 26 de dezembro de 2011.

INSTITUTO BRASILEIRO DE GEOGRAFIA E ESTATÍSTICA. Censo Demográfico 2010: Santa Maria de Jetibá. Disponível em http://www.ibge.gov.br/cidadesat. Acessado em 26 de dezembro de 2011.

JUSTINIANO, E. F. (2009). Registro fotográfico. En: Venturi, L. A. B. (Edit.). Praticando Geografia: Técnicas de campo e laboratório. São Paulo, Oficina de Textos, 187-196.

Macente, L. B.; SANTOS, E. G.; ZANDONADE, E. (2009). Tentativas de suicídio e suicídio em município de cultura Pomerana no interior do estado do Espírito Santo. Instituto de Psiquiatria da Universidade Federal do Rio de Janeiro. Jornal Brasileiro de Psiquiatria, 58/4, 238-244.

MEDEIROS, R. (1997). Espirito Santo: encontro de raças. Rio de Janeiro, Reproarte.

MORAES, C. (2004). Geografia do Espirito Santo. Vitória, Fundação Cultural do Espírito Santo.

PERRONE, A.; MOREIRA, T. H. L. História e Geografia do Espírito Santo. Vitória, Sodré.

PIANA, C. F. B.; MACHADO; A. A. SELAU, L. P. R. (2009). Estatística básica: versão preliminar. Pelotas, Universidade Federal de Pelotas.

PORTUGUEZ, A. P. (2005). Diagnóstico rural participativo do município de e Santa Maria de Jetibá (ES): Relatório de consultoria. Vitória, IPEMA.

PORTUGUEZ, A. P. (2007). Diagnóstico participativo para o desenvolvimento do turismo rural. En: Seabra, G. (Edit.). Turismo de base local: identidade cultural e desenvolvimento regional. João Pessoa, Universidade Federal da Paraíba. 189-110.

PREFEITURA MUNICIPAL DE SANTA MARIA DE JETIBÁ. (2001). Dados municipais. Santa Maria de Jetibá, PMSMJ.

RÖLKE, H. R. (1996). Descobrindo raizes: aspectos geográficos, históricos e culturais da Pomerânia. Vitória, Universidade Federal do Espírito Santo. 
SILVA, J. M. (2009). A análise do discurso e pesquisa qualitativa na geografia. En: Ramires, J. C. L.; Pessôa, V. L. S. (Edit.). Geografia e pesquisa qualitativa: nas trilhas da investigação. Uberlândia, Assis, 91-122. 